\title{
Correction to: Monoclon Antib Immunodiagn Immunotherap 2016;35(1):25-31
}

N THE FEBRUARY 2016 issue of Monoclonal Antibodies in Immunodiagnosis and Immunotherapy (vol. 35, no. 1,
pp. 25-31), in the article entitled, "Analysis of aDR5scFv with Specific Identification and Function" by Xiaofeng Cheng
et al., a figure that had been previously published in a different article was inadvertently included in the final manuscript.

Figure 1B has been removed from the article and its mention in the figure legend has been deleted. The corrected Figure and corresponding legend are shown below. The online version has been corrected to reflect these changes.

The authors wish to apologize for the error.

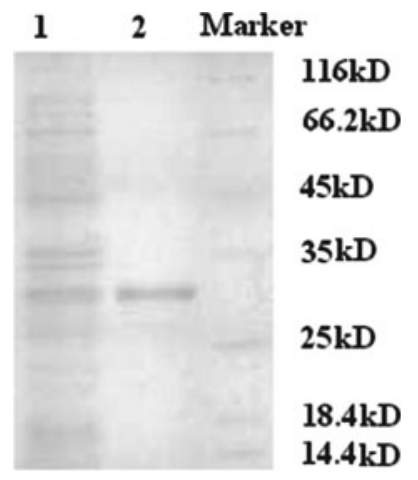

FIG. 1. Identification of the specification of anti-human death receptor 5 (DR5) single-chain fixed-variable (scFv) molecules by enzyme-linked immunosorbent assay. Protein expression graph of gene engineering Escherichia coli with aDR5-scFv. (1) Expressional protein induced $12 \mathrm{~h}$ by IPTG; (2) purified $\mathrm{scFv}$ protein. 